\title{
Identidad regional y actores: una experiencia de intervención sociológica en el valle de San Quintín, Baja California
}

\author{
Laura Velasco Ortiz*
}

Resumen: El artículo presenta la sistematización de la intervención sociológica durante dos años, con un grupo de activistas movilizados en la región de exportación agrícola conocida como valle de San Quintín — en la frontera entre México y Estados Unidos-, para estudiar el surgimiento de la identidad regional, a través de la movilización de trabajadores agrícolas y residentes, en las dos últimas décadas del siglo xx. En el curso de la investigación para definir la identidad regional, se encontró una transformación de la identidad del movimiento, ligada a los cambios macroestructurales de la zona y la lucha en contra de la exclusión.

Palabras clave: identidad regional, actores, intervención sociológica, acción colectiva, inmigración y etnicidad.

Abstract: This article presents the systematization of a two-year sociological intervention among a group of activists in the agricultural export region known as the San Quintin valley--on the border between Mexico and the United States--which aimed to study the emergence of a regional

* El Colegio de la Frontera Norte (COLEF). Carretera Escénica Tijuana-Ensenada, km. 18.5, San Antonio del Mar, C.P. 22560, Tijuana, Baja California, México. Correo electrónico: lvelasco (a)colef.mx 
identity due to the mobilization of residents and agricultural workers during the last two decades of the twentieth century. In the course of our research to define a regional identity, we found a transformation of the identity of the movement which is linked to macro-structural changes in the area and a struggle against exclusion.

Key words: regional identity, actors, sociological intervention, collective action, immigration and ethnicity.

\section{Introducción}

Hace casi treinta años el valle de San Quintín no existía como región. En la década de 1980 y mediados de la siguiente se hacía referencia a él como un lugar del estado de Baja California, muy cerca de la frontera oeste de México con Estados Unidos, (véase figura 1) donde rancheros y trabajadores se enfrentaban de manera constante, en torno a los salarios y condiciones de trabajo. A fines de los años ochenta, los periódicos regionales documentaron las protestas que grupos de jornaleros protagonizaron por los salarios bajos con que se pagaban las labores agrícolas. La magnitud de ellas paralizó los campos de cultivo y el gobernador tuvo que intervenir para dirimir el conflicto entre empleados y empresarios.

Continuaron las movilizaciones en torno a las condiciones laborales, y se extendieron a los años noventa, pero con algunos cambios. Por ejemplo, en 1999 los periódicos dieron cuenta de la quema de patrullas, camiones y un empaque en protesta por la retención de salarios de parte de una empresa agrícola (Cruz Aguirre 1999, 13). En esa ocasión intervino la delegación de la Secretaría del Trabajo, apostada en San Quintín.

Entre las huelgas de los años ochenta y las protestas de los noventa, además del tiempo también medió un cambio en el grado de organización de la protesta y la instancia de gobierno que intervino. En poco más de diez años, los problemas laborales se canalizaron a través de protestas espontáneas con líderes coyunturales y no de 
organismos laborales, como había sucedido en la década de 1980 cuando fue evidente la presencia de la autoridad local.

Estos cambios en las movilizaciones parecían mostrar, en forma incipiente, otra modificación demográfica y social: el asentamiento de miles de trabajadores y sus familias en la región. El escenario nuevo desatado por ese proceso de asentamiento pareciera haber restado energía social a los movimientos laborales, en beneficio de los residenciales, tras el abandono de la movilidad circular de una cantidad considerable de los trabajadores, que caracterizaba a la corriente migratoria de los años ochenta. En 1996, los jornaleros agrícolas en su nueva condición de residentes cerraron la única carretera que atraviesa la península bajacaliforniana, para demandar la reubicación de la clínica de salud más grande con la que contaría el valle, también surgieron grupos para tomar terrenos y demandar servicios urbanos (Ibid. 1996, 29). Cada vez más, las acciones colectivas por asuntos laborales, como los salarios o las jornadas, fueron disminuyendo su visibilidad y capacidad organizativa, y se hicieron más públicas las que exigían servicios y regularización de los terrenos. Los cambios en el rostro de los actores colectivos parecían ser parte de la transformación macroestructural, en el ámbito del mercado laboral y la dinámica demográfica.

El objetivo de este artículo es sistematizar la metodología seguida para estudiar la visión de los actores sobre esta transformación regional, en particular de las organizaciones de trabajadores y residentes, quienes han sido los protagonistas de las movilizaciones descritas.

Los estudios sobre actores regionales pocas veces presentan su metodología, lo que dificulta la acumulación de conocimiento sobre cómo realizar la investigación en esta área. A su vez, existe literatura abundante sobre la metodología para analizar la acción colectiva, como la colaboración, intervención o los grupos focales con pocos estudios de caso. Este artículo intenta hacer un aporte presentando en forma crítica la aplicación de la intervención sociológica, para el estudio de los actores en el valle de San Quintín, Baja California, con los ajustes realizados sobre la experiencia de los obreros franceses a la situación de los trabajadores agrícolas en una región mexicana, para hacer viable el método propuesto por Touraine (1981). La in- 
tervención sociológica permite estudiar la identidad regional desde los actores, en especial el surgimiento de la región como espacio de adscripción y disputa. La relación con los sujetos de estudio supone la coincidencia investigador-activistas del valor político del proyecto de la acción colectiva.

\section{Figura 1}

Localización del valle de San Quintín, Baja California

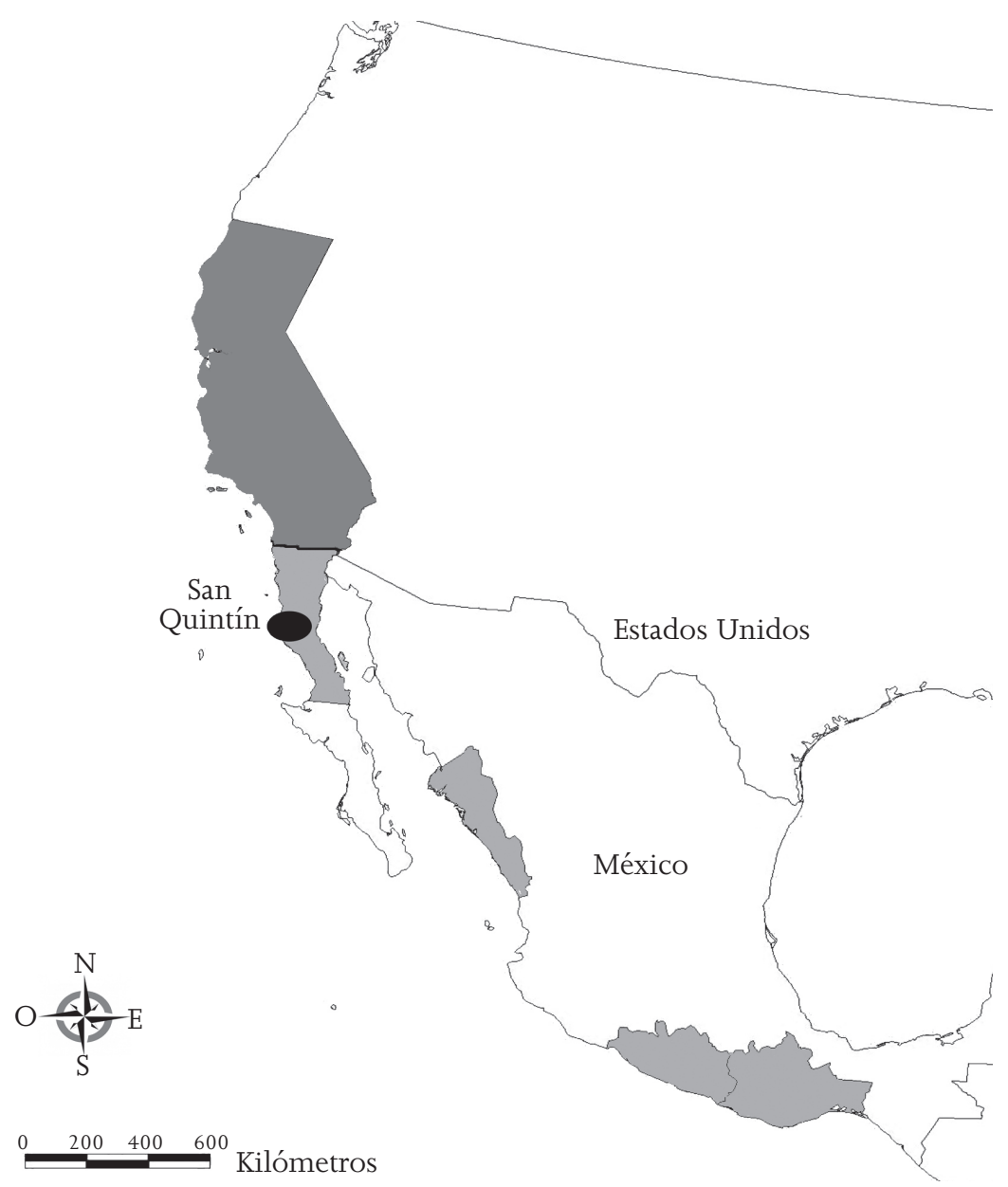

Fuente: elaborado con datos del proyecto "Migración, trabajo agrícola y etnicidad. La articulación de lo global, nacional y local en valle de San Quintín, Baja California”. Velasco Ortiz (2006). 


\section{Región, actores e identidad regional: una aproximación metodológica}

Las regiones se pueden estudiar desde distintas perspectivas conceptuales o dimensiones analíticas, pero a la vez con diferentes metodologías. Un reto constante es lograr una aproximación consistente en términos epistemológicos, que permita sintonía entre los datos empíricos y la construcción conceptual. Al alimentar esta última con el sentido que los sujetos dan a sus acciones es posible hablar de una validez de constructo interpretativa. Según Passeron (1991), la posibilidad de captar ese sentido de la acción no requiere tanto una neutralidad respecto de él, sino más bien una empatía social con vigilancia epistemológica; es decir, ser conscientes de la posición de valor respecto de ese sentido.

Para esta investigación, con una aplicación de Giménez (1994), la región se definió en términos socioculturales como la contienda entre quienes participan en la construcción de la identidad regional. En sí mismo, el universo de actores en un territorio es un indicador de su naturaleza social y cultural, ya que en su acción expresan intereses y sentidos de la sociedad. Según Schmitt-Egner (2002, 181), los actores representan uno de los cuatro elementos que definen una región. ${ }^{1}$ Éstos tienen un papel importante en la construcción de las fronteras de inclusión y exclusión cultural a la comunidad regional y por lo tanto de la identidad regional.

De acuerdo con Rosaldo (1989), la identidad implica más la disputa por fijar las fronteras de distinción que compartir ciertos elementos culturales. Los individuos parecen reconocer más fácil lo propio cuando enfrentan a otros extraños. El señalamiento de Rosaldo sigue la línea de reflexión abierta por Barth $(1969,9-38)$ en los años setenta, sobre la importancia de la significación de las diferencias culturales que construyen fronteras culturales. Barth teorizaba sobre la identidad étnica, sin embargo es aplicable al estudio de la social en general.

\footnotetext{
${ }^{1}$ Los otros son: estructura, programa y medio ambiente. El mismo autor define a la región como "[...] una unidad espacial parcial de tamaño intermedio y de carácter intermedio cuyo substrato material está basado en el territorio [...]” (Ibid.).
} 
En la dinámica de significación de las diferencias que caracterizan al "nosotros" de los "otros" en el marco de un lugar específico, los actores juegan un papel crucial al ser los voceros y constructores de los emblemas de la identidad regional.

Los estudios sobre migración e identidad (Benmayor y Skotnes 2005; Rapport y Dawson 1998) confirman con mucha claridad la importancia del encuentro con "otros" diferentes culturalmente, para la reelaboración de lo propio. En el caso de una región joven como el valle de San Quintín, fundada por colonos e inmigrantes, sucede un proceso muy parecido al observado en Estados Unidos, donde los inmigrantes más antiguos se convierten en los nativos, y las olas sucesivas representan el papel de extranjeros. En la literatura sobre migración, ese proceso recibe el nombre de nativización y se define como el arraigo poblacional paulatino, que implica apego a un territorio con un sentido de apropiación excluyente respecto a los recién llegados (Ngai 1999, 69-70).

En México, la industrialización llegó casi veinte años tarde al medio rural, y generó flujos de migración que fundaron poblados nuevos en zonas distintas del país. El comportamiento de esas migraciones fue diferente al de las urbanas; sus rasgos principales fueron temporalidad cíclica y movilidad alta, que no se agotaban en el territorio nacional sino que articulaban sus regiones agrícolas con las de Estados Unidos. Algunas de éstas se constituyeron socialmente sobre la base del encuentro inicial entre patrones y trabajadores procedentes de diversos lugares del país. Sin embargo, conforme se fue gestando el proceso de asentamiento y la población se fue diferenciando, los inmigrantes nuevos ya encontraban a "residentes nativos", quienes aludían al tiempo de estancia como una vía para distinguirse de los recién llegados (Du Bry 2003). Estos encuentros y disputas identitarias funcionan en la vida diaria en distintos ámbitos, sin embargo el de los actores sociales es uno privilegiado por su importancia, para definir las identidades regionales. Estas disputas o conflictos no necesariamente son disruptivos de la vida comunitaria; como lo señala Giménez $(1994,166)$, son un factor esencial de la dinámica de la región y deben ser tomados en cuenta para definir su especificidad. 
La aproximación de los actores sociales es útil en el estudio de una región joven, que en las últimas tres décadas ha experimentado una diferenciación rápida y movilización en torno a la integración social. Este valle es un espacio de confrontación entre personas que luchan en torno a diferentes temas o situaciones de conflicto: a) las condiciones de trabajo; b) las condiciones de reproducción de la fuerza laboral y c) el reconocimiento como integrantes de una comunidad territorial nueva. La hipótesis es que la relación de dominación que organiza el desempeño de los actores sociales en la región está fundada en los vínculos de trabajo agrícola, y se ha extendido a la lucha por las condiciones de reproducción de la fuerza laboral, en particular de la vivienda y la apropiación del territorio con una intervención escasa del gobierno.

El reto de captar la construcción social de la región, desde la acción de la gente, llevó a la búsqueda de metodologías apropiadas. La intervención sociológica es un método de investigación que parte del reconocimiento de la capacidad de los actores sociales para reflexionar sobre sí mismos y sus actividades (Touraine 1981). La teoría que lo respalda supone que el objetivo de la sociología es estudiar a dichos actores, ya que considera que la sociedad es antes que nada producto de la acción social, y que ellos se enfrentan entre sí con orientaciones culturales de referencia en el marco de relaciones de dominación, y luchan por definir la dirección de la historia.

Según esta perspectiva teórica, el movimiento social se define como la acción colectiva organizada, a través de la cual un actor de clase lucha por el control social de la historicidad en un contexto particular. En esta investigación se ajusta la definición de condición de clase marxista a la de clase de Bourdieu $(2002,98)$, como condición de existencia, y más tarde retomada por Kearney $(2008,90)$ para distinguir dos sentidos del concepto de clase, como identidad y a la vez como relación y proceso asociado al valor económico, lo cual permite pensar la etnicidad como un entramado de posiciones y relaciones sociales que es fuente de clasificación y jerarquización y a la vez de exclusión. Sin embargo, la identidad étnica no necesariamente precede al conflicto social, más bien es un resultado de la contienda por producirla o recrearla en forma positiva y de igual forma frente a otros (Martínez 2008, 73). De tal manera que la ac- 
ción colectiva puede implicar una lucha por la participación igualitaria o no excluyente en la construcción de la identidad regional.

Con estos ajustes, se presenta una definición operativa de movimiento social, específica de esta zona, como el conjunto de organizaciones de tipo laboral, residencial y étnico-cultural, que comparten una posición subordinada en la estructura de dominación de la producción agrícola moderna y que luchan, entre otras cosas, por la apropiación territorial y la adscripción regional.

El método de intervención sociológica supone tres etapas, en las cuales un grupo de integrantes del movimiento social estudiado discute entre sí y con un conjunto de aliados y adversarios sobre la agenda. En esta perspectiva metodológica, el investigador interviene para generar la discusión y el encuentro con otros actores; asimismo, elabora varias hipótesis, y las pone a consideración de los actores. En su forma ortodoxa, el método considera tres etapas a partir de un primer encuentro entre los actores del movimiento que se analiza. Sin embargo, se hizo un ajuste al introducir una etapa preliminar de definición del sujeto del movimiento y la reconstrucción del contexto de actores sociales, que delimitan el campo de la acción colectiva; ${ }^{2}$ para lo cual se realizaron entrevistas grabadas, que fueron transcritas para su análisis, con informantes privilegiados como líderes, activistas, periodistas y funcionarios, con la finalidad de conocer el universo de organizaciones, y de esta forma hacer una primera definición de los aliados y contendientes y los temas de disputa.

Las etapas transcurrieron entre 2004 y 2005, a través de tres talleres de discusión de un día cada uno, con lapsos de un mes entre ellos y otro con la participación de activistas, funcionarios de gobierno y eclesiásticos, empresarios agrícolas, de transporte y profesores reconocidos por la comunidad. Estos talleres fueron videograbados con permiso de los asistentes y se transcribieron las discusiones. Además, durante las sesiones se tomaron notas etnográficas sobre aspectos de la interacción que no se registraban en la grabación.

\footnotetext{
${ }^{2}$ Este proyecto se benefició de la experiencia de investigación reseñada por Kevin McDonald (2002, 247-260).
} 


\section{Intervención sociológica con actores regionales}

En el valle de San Quintín hay gran presencia de empresas extranjeras especializadas en cultivos de exportación. Las relaciones sociales ahí se caracterizan por la diferenciación étnica, como consecuencia de la inmigración de indígenas procedentes de las zonas más pobres del sur de México; 52.3 por ciento de los habitantes del valle nació en lugares como: Oaxaca (39.1 por ciento), Sinaloa (13.9), Michoacán (8.5), Guerrero (6) y Veracruz (4.5).Y 16 por ciento de las personas, de cinco años y más, habla lenguas indígenas como mixteco, triqui y zapoteco (Colef-Consejo Estatal de Población de Baja California, CONEPO 2003).

La subordinación aguda de los indígenas en la estructura de relaciones sociales se filtra en las alianzas entre actores y sus vínculos con el gobierno regional. Dicha posición también origina su discriminación étnica en el mercado de trabajo agrícola; 82 por ciento de los hablantes de lengua indígena labora, en su mayoría, como peón o jornalero agrícola (77.6 por ciento). Esta condición cambia si se les ve como inmigrantes ( 52 por ciento) o bien como nacidos en la región (23) (Ibid. 2003).

Los indígenas llegan en mayor cantidad a la zona; nueve de cada diez hablantes de una lengua autóctona nacieron en otro estado, a diferencia de cuatro de cada diez que sólo halan español, que nacieron en otra entidad. La diversidad de lenguas indígenas se asocia de manera directa con el fenómeno migratorio de la región. Y todas tienen su origen cultural en otro estado de la república mexicana; las más habladas son mixteco (78.72 por ciento), triqui (11.74) y zapoteco (4.26).

En la última década hubo una flexibilización creciente en las relaciones de trabajo, que se tornaron inestables y aumentó la intermediación. Esto, junto con las políticas sindicales corporativas, ha desalentado las movilizaciones laborales. Además, la energía social requerida en el proceso de asentamiento residencial ha desplazado el foco de atención de las organizaciones hacia demandas asociadas a los terrenos, la construcción de vivienda y dotación de servicios. En la región, dicho proceso ha tenido consecuencias demográficas notorias en las últimas décadas. Entre 1990 y 2000 la población 
en el valle casi se duplicó, pasó de 38151 a 74427 habitantes (COlef-Consejo Nacional de Ciencia y Tecnología, CONACYT 2003). También hubo cambios residenciales importantes: la disminución de los campamentos para trabajadores en circulación y el incremento de las colonias populares, a la par de la diferenciación social en términos laborales y étnicos. Por ejemplo, la proporción de los jornaleros agrícolas, que residía en campamentos durante la temporada alta, pasó de dos terceras partes a una entre 1989 y 1999 (Instituto Nacional Indigenista, INI y Programa de Atención a Jornaleros Agrícolas, Pronjag, citado por Velasco 2002, 71), sólo entre 1996 y 1999 las colonias aumentaron, de 16 a 43 y a principios de 2004 ya sumaban 62 (Ibid.)

Buena parte de los colonos nuevos ya no son tan vulnerables a los cambios de temporada agrícola, puesto que el empleo se ha extendido durante todo el año; asimismo el crecimiento poblacional ha propiciado el surgimiento de posibilidades en otros sectores como los servicios y el comercio regional, contribuyendo así a la diversificación creciente de los mercados laborales.

A la par del proceso de asentamiento han aparecido instancias de gobierno local y un estrato de profesionales y comerciantes en pequeño, que se han constituido en asociaciones o clubes, que apelan a una identidad nativista y a una representación ante el gobierno. Así disputan el espacio público ganado por las organizaciones de trabajadores agrícolas hasta la década de 1980, y en particular han generado discursos sobre el futuro político y la identidad de la región.

Tanto el cambio del foco del conflicto laboral hacia el residencial, la aparición de actores nuevos, así como la sustitución del empresariado por el gobierno local para presentar las demandas han generado un perfil multifacético en las organizaciones para responder a una diversidad amplia de necesidades y de relaciones sociales como las laborales, residenciales, institucionales y comunitarias, y han ubicado al gobierno como uno de los interlocutores más importantes. ${ }^{3}$

\footnotetext{
${ }^{3}$ Los hallazgos de la investigación confirman lo señalado por Edelman $(1991,186)$ de que no obstante la disminución del tamaño del Estado, sigue siendo una fuente de recursos central para las poblaciones pobres.
} 
A continuación se presenta la experiencia metodológica para el estudio de los actores y la contienda por la identidad regional, en cuyo fondo aparecen los cambios sociales y tecnológicos que han dado pie al asentamiento poblacional acelerado, entre ellos los de la migración y la producción agrícola.

\section{Las etapas y ajuste del método de intervención sociológica}

Como ya se mencionó, aquí se ajustó el método de intervención sociológica, debido a que éste supone que el investigador "conoce” el universo de actores en forma precisa. Si bien, la experiencia previa permitía plantear hipótesis al respecto, la velocidad de transformación de la región hizo cuestionar tal supuesto metodológico. La estructuración de un obrero posee cierto grado de estabilidad en una sociedad como la francesa, con regulaciones laborales bien definidas y una tradición sindical amplia, sin embargo, en una región donde los marcos jurídicos en dicho terreno no son claros y los propios trabajadores están en proceso de transición de temporales a residentes, fue indispensable reconstruir ese universo con trabajo de campo en profundidad.

Primera etapa: los sujetos de la acción colectiva

A lo largo de la primera etapa, realizada de junio de 2004 a junio de 2005, se definió como sujeto de la acción colectiva al conjunto de organizaciones, asociaciones y comités de colonias que compartían entre sí una posición subordinada en la estructura de dominación de la producción agrícola moderna de la región. Esto se llevó a cabo a través de pláticas informales y entrevistas en profundidad con activistas de las agrupaciones de trabajadores agrícolas y de residentes. También se entrevistó a personas o activistas de grupos de profesionistas, empresarios agrícolas, comerciantes o funcionarios eclesiásticos. Como se observa en la figura 2, el universo de interlocutores, ya sea en antagonismo o solidaridad, es más complejo de lo que por 
lo general otros estudios conceden a la relación entre trabajadores y patrones agrícolas. En la medida en que San Quintín ha experimentado el proceso de asentamiento residencial, su estructura social y económica se ha tornado más complicada. Han surgido personas que disputan el campo de acción social y la representación de los intereses regionales, en busca de la interlocución con el gobierno.

\section{Figura 2}

Actores, organizaciones y espacios de confrontación

\begin{tabular}{|c|c|c|}
\hline Actores & Grupo militante & $\begin{array}{l}\text { Espacio de relación o } \\
\text { confrontación }\end{array}$ \\
\hline $\begin{array}{l}\text { Jornaleros agrícolas- } \\
\text { residentes }\end{array}$ & $\begin{array}{l}\text { Organizaciones, } \\
\text { comités de colonias y } \\
\text { asociaciones pro pueblos }\end{array}$ & $\begin{array}{l}\text { Político-organizativo, } \\
\text { laboral, residencial } \\
\text { y étnico }\end{array}$ \\
\hline \multicolumn{3}{|l|}{ Aliados o adversarios } \\
\hline $\begin{array}{l}\text { Los nativistas o localistas } \\
\text { (empresarios servicios, } \\
\text { profesionistas, } \\
\text { comerciantes) }\end{array}$ & $\begin{array}{l}\text { Agrupación Baja California } \\
\text { de San Quintín (1994) } \\
\text { Comité pro municipio }\end{array}$ & $\begin{array}{l}\text { Política local-identidad } \\
\text { regional }\end{array}$ \\
\hline Eclesiásticos & Cristo por su Mundo & Religioso y comunitario \\
\hline Empresarios agrícolas & $\begin{array}{l}\text { Pequeños y medianos } \\
\text { empresarios }\end{array}$ & Laboral \\
\hline $\begin{array}{l}\text { Funcionarios de } \\
\text { gobierno }\end{array}$ & $\begin{array}{l}\text { Programa de Atención a los } \\
\text { Jornaleros Agrícolas, Secretaría } \\
\text { de Educación Pública, Instituto } \\
\text { Mexicano del Seguro Social } \\
\text { y secretarías del Trabajo y } \\
\text { Previsión Social y de Gobierno }\end{array}$ & Institucional \\
\hline
\end{tabular}

Fuente: elaboración propia, con datos del trabajo de campo.

Como aparece en la figura 2, el grupo de estudio lo integraron los activistas de organizaciones sociales y políticas constituidas formalmente en torno a intereses laborales, residenciales o étnico-culturales. También se incluyeron los representantes de comités de co- 
lonias con orientación micro-local, enfocados en la residencia y los servicios, así como las asociaciones de índole cultural como las pro pueblos y las de mujeres. Los criterios centrales de selección fueron el grado de involucramiento de los activistas en las organizaciones, su capacidad de reflexión sobre su propia acción y su contribución a la diferenciación interna del grupo de estudio.

En esta etapa se analizó la contribución potencial de cada participante en el taller en forma individual y como parte de un colectivo. Y una vez revisadas las entrevistas, el grupo total quedó constituido por seis activistas de organizaciones político-sociales, seis representantes de comités de colonias, dos de asociaciones pro pueblos y dos profesores indígenas, con reconocimiento de su comunidad de referencia. En esta etapa se puso a consideración de los activistas del movimiento la idea de impartir los talleres, con el fin de encontrar consenso e interés entre los participantes potenciales, así como detectar las condiciones para lograr un espacio de diálogo entre actores con grados diferentes de confrontación. La fragmentación y el faccionalismo era parte del escenario y amenazaba la impartición de los talleres. Esta etapa duró casi un año, tiempo que se llevó hacer las entrevistas, transcribirlas y analizarlas, además se diseñaron los talleres de discusión. También se descubrió a los profesionistas y funcionarios eclesiásticos, que al principio no estaban contemplados.

A través de la entrevista con informantes privilegiados se detectó una serie de asociaciones y clubes con un perfil totalmente distinto al mencionado en la literatura y no advertido en el trabajo de campo anterior, como el Club Rotario, los grupos Madrugadores y el de Baja California, la Asociación de Transportistas de San Quintín y el Comité Pro Municipalización, constituidas por profesionistas, comerciantes y empresarios, algunos de los cuales llegaron junto con la ampliación de la presencia institucional y gubernamental de la década de 1990; por ejemplo, las oficinas de las delegaciones municipales, de los representantes del gobierno estatal e instancias principales como el Sistema para el Desarrollo Integral de la Famila, Secretaría del Trabajo, Comisión para la Regularización de la Tenencia de la Tierra del Estado, la Junta de Conciliación y Arbitraje y la Secretaría de Agricultura, Ganadería, Desarrollo Rural, Pesca y Alimentación y otras en el año 2000. 
Esta etapa de campo también permitió detectar a las iglesias no católicas, que desde los años setenta realizan un trabajo intenso de evangelización en el valle; en 2003 había 77 de ellas, frente a 20 católicas en las dos delegaciones más pobladas de la región y con mayor presencia de indígenas. ${ }^{4}$

Segunda etapa:

identidad colectiva, historia común y divergencias

En esta etapa el objetivo fue definir los elementos de la identidad del grupo movilizado, es decir, los que los hacen ser parte de un "nosotros" más allá de la coyuntura del movimiento o una acción colectiva, para obtener indicios de la existencia de una zona sociocultural (Giménez 1994, 165) al rastrear el pasado vivido en común por la colectividad movilizada, y que de alguna forma refiere a la asentada en una porción del territorio regional.

Esta etapa incluyó el diseño de la dinámica y contenido del primer taller de discusión, así como la estrategia para convocar a los activistas de organizaciones laborales y comités de residentes, quienes eran el núcleo del movimiento. El taller se impartió el 24 de julio de 2005, en un hotel durante todo el día; los participantes recibieron su sueldo, y ello les permitió estar relajados, sin la preocupación de perder el salario de un día.

El moderador fue un activista indígena de otra región agrícola con conocimiento en grupos focales, y simpatizaba con los objetivos de las organizaciones a las cuales pertenecían los asistentes. Él intervino en el diseño de los talleres y su análisis. La investigadora y los dos ayudantes fungieron como testigos activos en las sesiones, tomando notas y en el registro audiovisual.

La empatía política abierta mostrada por el moderador facilitó la apertura de los participantes, quienes constituyeron un grupo de discusión y reflexiones sobre sus experiencias, logros, obstáculos e interlocutores como organizaciones. El investigador funcionó como guía de la reunión, y propuso algunas líneas de discusión (tomadas de las entrevistas en profundidad), y las puso a consideración de

${ }^{4}$ Cédulas de observación de campo, 2003. 
todos, como las siguientes: a) origen de las organizaciones-movimiento; b) luchas y logros principales; c) experiencias y fuentes importantes de conflicto en las organizaciones; d) relación con el gobierno; e) relación con los empresarios o rancheros agrícolas; f) relación con otros actores regionales e intermediarios laborales; g) el papel de las organizaciones en el proceso de asentamiento y h) los interlocutores principales; quiénes los han apoyado y quiénes han obstaculizado sus actividades u objetivos (aliados y adversarios).

El objetivo de esta etapa fue conocer el contenido de la unidad político-cultural del movimiento social. El grupo funciona como representante de éste, y a la vez como un testigo que analiza sus experiencias pasadas, de las que construyó una historia común más allá de la individualidad de cada persona y organización, que incluyó dos momentos: uno ubicado en los años ochenta, con una serie de movilizaciones alrededor de demandas ligadas al trabajo agrícola y la procuración de la justicia, como indígenas, y otro en los años noventa, con una protesta ligada al asentamiento en las colonias, regularización de los terrenos, construcción de viviendas y obtención de servicios.

En el taller surgieron, como interlocutores, los funcionarios de instancias de gobierno, con quienes disputan las prioridades regionales. La construcción de un adversario común -los empresarios o el gobierno-, les otorga una imagen global cohesionada en torno a la experiencia del conflicto.

Además de la propuesta analítica de Touraine (1981), se fijó la atención en la heterogeneidad de este movimiento y los conflictos internos que sostiene tal unidad. La idea sobre la importancia de enfatizar cómo se negocian las diferencias para lograr las unidades coyunturales de los movimientos sociales (Melucci 1992 y 1989) llevó a distinguir las asociaciones civiles o sindicales, con una tradición opositora con un discurso de clase, frente a los comités de colonias que se habían formado como resultado de la acción gubernamental ante el asentamiento, y que en alianza con las primeras - o con sus mismos liderazgos- se mueven para lograr reconocimiento como residentes ante el gobierno que les otorgue recursos muy específicos, como ciudadanos locales. 
Tercera etapa: identidad en contraste y la identidad sanquintense

Una vez definidos los contornos temáticos que dan unidad al movimiento y algunos de las líneas de conflicto interno, que a su vez definen el perfil de sujeto en movimiento, la tercera etapa persiguió poner a prueba esa identidad, pero ahora en contraste con los "otros". Y comenzó con el diseño y convocatoria de los interlocutores (aliados y adversarios), definidos en las discusiones previas para reunirse y trabajar en un segundo taller llevado a cabo el 14 de agosto de 2005, también en una jornada completa.

En esta etapa el grupo definió su identidad en contraste con otros actores regionales, quienes fueron revelados en el primer taller como los interlocutores más importantes, ya sea en enfrentamiento o alianza. El investigador invitó a algunos de ellos a participar para dialogar sobre los puntos definidos por el grupo objetivo como los temas del encuentro. La agenda consideró tres elementos: a) la caracterización del valle desde el punto de vista de todos los participantes, sujetos del momento e interlocutores (aliados y adversarios); b) la identificación de las áreas de conflicto en la región en los últimos diez años y c) la reflexión sobre los problemas de intervención y coordinación para resolverlos.

La exploración de campo y la realización de entrevistas en profundidad permitieron ubicar a los actores que aparecían constantemente como parte del universo de acción colectiva del grupo. En la figura 2 aparecen cuatro tipos: los nativistas o regionalistas, constituidos sobre todo por profesionistas, comerciantes y algunos empresarios de servicios; los eclesiásticos —en particular los no católicos-; los funcionarios de gobierno y los empresarios agrícolas.

El grupo objetivo enfrentó las imágenes externas y tuvo oportunidad de modificar las representaciones del adversario, construidas en los espacios de enfrentamiento por las surgidas en la interacción cara a cara en los talleres. Así aparecieron las imágenes de migrante, trabajador del campo e indígena, como características del sujeto de la movilización, pero a la vez de exclusión. También surgió el concepto de residente frente al de migrante, y el sanquintense como una sombrilla conceptual para abarcar a todos —aliados y no aliados-. Aunque las discusiones sobre la prioridad de los asuntos por resol- 
ver y quiénes tenían legitimidad para intervenir dividieron a los participantes, todos coincidieron en que existía una región debido a la historia, cultura y economía, con límites geográficos claros.

Esta situación pone a prueba la unidad ideológica del discurso en contra de los adversarios. El principio de oposición que organiza las identidades aflora en el encuentro con los que se definen como diferentes en el campo político, ya sea que a veces se les ubique como adversarios o bien como aliados. En el momento de realizar los talleres, a principios de este siglo, fue evidente que el empresario ya no era el "adversario", sino que el gobierno era el nuevo interlocutor antagónico de las demandas de los movilizados. Aun cuando los temas laborales seguían presentes, como fuentes de acción colectiva, se responsabilizaba al gobierno por la no aplicación de la ley o la ausencia de protección de los derechos laborales. Además, éste era el interlocutor en la regularización de los terrenos y la dotación de servicios. También fue posible registrar la disputa con un tipo de actores que respondían a la participación de los habitantes de la región en el espacio público. Esta era una polémica menos marcada, que la dirigida al gobierno o los empresarios, y cuyos interlocutores eran los comerciantes grandes y pequeños y los profesionistas. Sector representado en una serie de colectivos o asociaciones con un discurso regional, que se ha dado a la tarea de revisar la historia y conformar una idea de lo sanquintense. Fue posible registrar una disputa por los elementos culturales que debieran constituir lo sanquintense, y donde está presente la asociación entre lo que venía de fuera con los inmigrantes. El proceso de arraigo parece pasar por la conversión a "ser de aquí", y descalificar a los que vienen de fuera, como extraños, en particular al referirse a los inmigrantes indígenas. Los mismos sujetos del movimiento social rechazaron ser nombrados "inmigrantes", ya que el término se utilizaba como una vía para descalificar o deslegitimar su derecho a participar en el destino de la zona.

La región surge como un espacio de encuentro con los enemigos, y donde hay una polémica por definir las características del sanquintense, cuya identidad aparece como motivo de disputa y unión entre los actores. En la apropiación de esta identidad, los agentes gubernamentales tienen un peso fundamental y se vuelven inter- 
locutores centrales, pero también quienes representan al "ideal" de ciudadano sanquintense en el espacio público.

Cuarta etapa: el horizonte regional de los actores

Las etapas dos y tres pueden calificarse como de autoanálisis grupal en torno a la unidad y la oposición. En la cuarta, el investigador presenta la sistematización de las discusiones y algunas hipótesis sobre los ejes de la unidad, la oposición y el campo de las relaciones en el contexto regional y global. Para lo cual, el equipo se dio a la tarea de sistematizar los resultados de las tres etapas anteriores, incluso de las entrevistas exploratorias y los talleres, además de generar un conjunto de hipótesis sobre los resultados, con la finalidad de ponerlas a consideración de los sujetos del movimiento en un tercer taller, realizado el 4 de septiembre de 2005.

Al inicio de la sesión sólo el grupo objetivo recibió documentos de trabajo. Por ejemplo, se les entregó un informe ejecutivo de las estadísticas socioeconómicas del valle, y se proyectaron algunas imágenes de los talleres, así como las líneas de discusión principales y algunas hipótesis al respecto.

Los participantes comentaron los documentos y exposiciones, evaluaron y criticaron la sistematización y las hipótesis del investigador, que se discutieron y reelaboraron en forma colectiva, y quedaron expresadas como sigue:

- Los activistas rebatieron la idea externa de la investigadora de la inexistencia de un movimiento social, sino más bien la presencia de un conjunto de actores que se mueven en forma aislada y fragmentada, con el argumento de que la ausencia de movilizaciones continuas no indica que sean incapaces de coordinarlas en cualquier momento, y además de que comparten una visión general acerca de la importancia de luchar por la justicia. Es decir, la constitución de un movimiento social no sólo ocurre gracias a la capacidad de movilización, sino que aunque haya manifestaciones aisladas, todas se organizan en torno a un objetivo común: una vida mejor y de condiciones de igualdad en el futuro. 
- La investigación planteó que existe una tendencia a reivindicar beneficios muy particulares con base en intereses locales, como servicios e infraestructura de las colonias, las ganancias de programas de la política social y el interés por la reproducción de tradiciones o discursos de especificidad étnica (de colonias o étnicos), que no logran articular una visión de región. Además, las organizaciones tienen un grado alto de informalidad y atienden un rango grande de necesidades que van de lo laboral a lo doméstico o cultural. No obstante que los participantes hicieron suyas estas hipótesis, las matizaron con la reflexión de que esas luchas locales se inscriben en un deseo de ser sanquintenses y formar parte de la región. Las discusiones se dirigieron a inscribir su lucha en la idea de ser ciudadanos locales, para mejorar su condición de exclusión global, como trabajadores e inmigrantes indígenas.

- Es posible decir que existe una competencia entre las organizaciones sociales por los recursos y la representación política, con poco conocimiento de otros actores que compiten también por los mismos recursos. Es decir, durante los talleres los activistas aún no tenían un diagnóstico del campo de actores y fuerzas donde inscriben sus luchas, ni lograban ubicar con quiénes podían establecer eventualmente alianzas estratégicas. El interlocutor principal de esta competencia fue el gobierno federal, con un giro hacia las instancias municipales y estatales en la última década.

- En el campo de las alianzas, la investigación mostró que, a diferencia de los empresarios, los trabajadores y residentes han logrado uniones políticas débiles a través de la frontera geopolítica; éstas se extienden mediante sus redes migratorias de orden familiar y de paisanaje, antes que de las organizaciones transnacionales. En tanto que los empresarios se mueven a través de la frontera geopolítica para comercializar y establecer nexos con sus pares de California y Sinaloa.

- La investigación también mostró que en la última década han surgido organizaciones de profesionistas con un discurso nativista en el espacio político, que está permeando las discusiones acerca de la identidad regional, donde lo extraño se asimila cons- 
tantemente con lo migrante e indígena, en forma muy cercana a la condición de trabajador agrícola. Por lo que lograr la adscripción como sanquintense es un motivo de lucha y apropiación para los grupos formados por jornaleros migrantes e indígenas. Ese discurso nativista está presente en el espacio público de la región tanto en actores sociales medios como en funcionarios de gobierno, y funge como marco ideológico a las condiciones laborales a las que son sometidos quienes trabajan la tierra.

Esta etapa final constituyó un momento de análisis sociológico, donde se intentó cruzar la interpretación de los asistentes con la del investigador en una condición de diálogo y negociación epistemológica entre dos estilos de construcción de conocimiento. El conjunto de etapas permitió explorar los principios básicos de la acción colectiva: la identidad y heterogeneidad, la oposición y la totalidad, al identificar a quienes consideran parte del movimiento y cómo se definen a sí mismos en su unidad, quiénes son sus adversarios y aliados y en qué tipo de relaciones sociales amplias inscriben su acción, o de qué son parte. El investigador funciona como un espejo que les permite sistematizar las discusiones propias, y ponerlas en un marco más amplio de análisis, donde los participantes hacen conexiones a las cuales no habrían podido llegar en forma individual.

\section{Hallazgos sobre actores, identidad regional y metodología}

A continuación se presenta un resumen de los hallazgos obtenidos en las etapas de la investigación. Todos los asistentes a los talleres estuvieron de acuerdo en que sí existe una región que se puede nombrar valle de San Quintín, y delimitarse desde las delegaciones Punta Colonet al norte, hasta El Rosario, al sur. Sin embargo, coincidieron en que la geografía no es suficiente, por lo que agregaron la actividad económica, la historia de la población y la vida cultural.

Sobre la economía, los participantes reconocieron que la región tiene un perfil agrícola, aunque expresaron su preocupación por di- 
versificarlo, para no depender sólo de la agricultura. Esta inquietud fue introducida por un empresario que recién dejaba la presidencia de la Asociación de Productores del Valle de San Quintín. En relación con el aspecto histórico, analizaron el papel de las migraciones para definir a la región. Las intervenciones sobre este punto se tornaron en particular apasionadas en torno a la idea de lo adecuado de seguir hablando de "migrantes" después de 10, 20 o 30 años de residir en el valle.

Las intervenciones de los líderes indígenas e inmigrantes se centraron en el derecho de residir y dejar de ser nombrados "migrantes" o "paisanos". El objetivo de ellas fue responderles a algunos empresarios de servicios y comerciantes sobre su diagnóstico acerca de la región dividida entre los que "ya estábamos" y los que llegaron después, del sur. Las expresiones "el sur" o "Oaxaca" estaban cargadas con un tinte étnico al que los funcionarios (casi todos originarios de Baja California) o bien los empresarios no querían aludir en forma directa. Algunos mencionaban el hecho de que "en el valle había más oaxaqueños que en Oaxaca”, o bien otro decía que todo estaba alterado porque si "uno viaja a Estados Unidos, ve que está lleno de mexicanos, va uno a Oaxaca y está lleno de ‘americanos' y aquí en San Quintín está lleno de oaxaqueños”. Es importante subrayar que estos empresarios son inmigrantes de segunda generación, originarios de Michoacán y otros de Ensenada. La polémica pareció enfocarse en la figura del inmigrante que caracterizaba a la región; en general ésta cobró un fuerte matiz étnico y de clase al definirse como jornalero agrícola de origen indígena.

Unas semanas antes del taller, uno de los protagonistas, empresario, ingeniero de profesión y originario de Ensenada, dijo en una entrevista: "A mí no me gusta que quieran venir a imponernos sus jarros de barro, sus bailes y sus trajes típicos; sí me gusta verlo en los museos, pero no en mi casa $[\ldots]$ no quiero que me impongan costumbres ajenas". Este tema de la imposición de lo "ajeno cultural" surgió varias veces, cuando se hacía referencia a las trasmisiones de la radiodifusora La Voz del Valle. ${ }^{5}$ Varios profesionistas y

\footnotetext{
${ }^{5}$ La estación fue fundada en 1992 a petición de la Central Independiente de Organizaciones Indígenas y Campesinas, ante el entonces INI.
} 
comerciantes opinaron que la radio no representaba lo que pasaba en el valle, porque sólo se dirigía a la población indígena ${ }^{6} \mathrm{o}$ a veces la nombran como la "radio triqui". Esto es lo que Balibar (1991, 26) llama racismo cultural, para referirse a la discriminación de un grupo étnico o nacional basado en sus tradiciones o costumbres, que sustituye al racismo físico, pero que mantiene la misma intensidad de conflicto.

La región fue fundada y ha sido poblada por inmigrantes que no sólo llegaron como trabajadores agrícolas sino como rancheros y luego empresarios. Todos tienen un pasado migrante con orígenes étnicos y de clase distintos; sin embargo, como sucede en otras partes del mundo, debido a ciertas condiciones materiales surge un proceso de arraigo que puede llamarse "nativización", en que las primeras generaciones buscan distinguirse y se asignan más derechos que los recién llegados, para definir el rumbo de la región. En el valle de San Quintín este proceso de nativización se empalma con el de estratificación o diferenciación social, a través del cual la población establece relaciones jerárquicas por su posición en el mercado laboral. Dicha diferenciación la van experimentando los propios migrantes en su vida cotidiana, por ejemplo al no habitar ya en un campamento o en una cuartería, sino en una casa con patio y servicios básicos. Asimismo, la diversificación ocupacional les permite a algunos trabajadores pasar de peón a regador o chofer, o tener un empleo en una oficina de gobierno, o bien se establezca como comerciante en una tienda de abarrotes.

Sin embargo, en el espacio de los actores sociales es donde ese proceso de diferenciación se expresa en torno a la lucha por definir la identidad de la región. Aunque es posible hablar de una diferenciación residencial y ocupacional, todavía tiene un vínculo muy estrecho con el sistema de producción agrícola. No existe otra fuente de empleo lo suficientemente fuerte como para generar otros grupos sociales; la presencia del gobierno ha tenido su repercusión en lo que se refiere a los profesionistas; el comercio sigue siendo

\footnotetext{
${ }^{6}$ Entrevista a Arturo Neri, director de La Voz del Valle del INI, 1996, realizada el 15 de marzo de 2003. En la actualidad el ins es la Comisión Nacional para el Desarrollo de los Pueblos Indígenas.
} 
de pequeña escala y ligado al trabajo agrícola. De tal forma que este sistema de producción sigue ordenando las relaciones y las jerarquías sociales.

Existe un desplazamiento del conflicto laboral hacia el problema de los residentes en torno a las tierras, viviendas y servicios. Las organizaciones de residentes han asumido la defensa y acción colectiva respecto a demandas puntuales en el ámbito laboral y la intermediación con el gobierno en otras áreas de gestión social o judicial.

La polarización dominante en los años ochenta entre jornaleros y empresarios encuentra ahora una mediación social en las categorías sociales nuevas conformadas por los profesionistas, comerciantes y pequeños empresarios. Estos últimos han iniciado un activismo en el campo de los medios de comunicación y la política local, con un discurso nativista. La fuerza y violencia con la que emergieron los trabajadores agrícolas en los años ochenta, y después los residentes, a través de organizaciones sociales, ha tenido una reacción reciente en estas asociaciones localistas que se nutren de profesionistas, Comerciantes y transportistas, quienes tratan de movilizar sus intereses e influir en la identidad de la región. Si bien es posible hablar de un espacio de actores sociales que dialogan y se enfrentan, lo cierto es que éste guarda una diversidad de intereses que sólo encuentra unidad en la idea de "región", como una comunidad geográfica, histórica y culturalmente diversa, cruzada por la desvalorización de los indígenas y trabajadores del campo como los culturalmente extraños. En este espacio los "migrantes" son los indígenas y jornaleros, por ello en las organizaciones populares hay una lucha intensa por autonombrarse sanquintenses, y despojarse de los adjetivos "paisano" o "migrante".

En el valle de San Quintín es difícil hablar de un movimiento social con un perfil único, lo que se observa es un conjunto de acciones colectivas protagonizadas por actores sociales que se definen por su condición de clase frente al trabajo agrícola, como residentes por su situación de colonos pobres e indígenas debido a su subordinación en el marco del Estado mexicano. Estas condiciones estructurales parecen conjuntarse en el momento actual de 
constitución cultural, en un foco de lucha asociado al arraigo y la adscripción territorial, por lo que el estatus de residentes emerge como el motor de la acción colectiva e identidad de los movilizados, sin perder su yuxtaposición con la de clase y la étnica.

Estas conclusiones fueron posibles gracias a la utilización del método de intervención sociológica, en la medida que permite una construcción de conocimiento sobre un "nosotros" en diálogo con los "otros", con quienes es difícil coincidir en la región en una situación de encuentro. La tarea del investigador es facilitar esos espacios y sistematizar los resultados, en un proceso empático con el sentido de la acción del grupo movilizado.

Los tres elementos del método: identidad, oposición y totalidad funcionaron con claridad a lo largo de la investigación, y permitieron que el conjunto de activistas concluyera con una reflexión sobre el nosotros, los otros y el campo total de la acción colectiva. La reflexión sobre la importancia de la región como arena geográficocultural de encuentro y desencuentro entre actores fue un hallazgo significativo para todos los participantes, incluso para los calificados como adversarios. En el conjunto de las organizaciones sujeto del movimiento existen algunas tensiones que es importante considerar entre las visiones de lo político bien diferenciado, y en el que parece intervenir la condición de género. Las mujeres son muy activas en los comités de colonias en torno a demandas residenciales, en tanto que los "viejos" líderes o dirigentes obreros eran en su mayoría hombres, que se ubicaban en un campo de lucha nacional. Ello trajo dificultades en la comunicación durante los talleres y en su posicionamiento frente a las autoridades.

También convocar a los funcionarios y empresarios fue particularmente difícil. Hubo cierta expresión de desconfianza hacia los objetivos de la investigación y los talleres. Sin embargo, los participantes mostraron mucha disposición a escuchar y hablar con los activistas, hubo una gran apertura e interés en los temas y puntos de vista, en especial de los funcionarios jóvenes. Estas actitudes disminuyeron la tensión que dominaba al principio; había cierta incertidumbre e incredulidad sobre la asistencia de funcionarios y empresarios y la imposibilidad de dialogar. 
Una crítica a la metodología que dio base a esta investigación es la idea preexistente acerca del énfasis en la historicidad del movimiento, que tenía en mente al actor como sujeto de clase social de corte marxista. Aquí se logró elucidar la existencia de un conjunto de actores que se movilizan en momentos distintos según definiciones de clase con matices importantes, y que están entrecruzadas con el género y la etnicidad. A la vez, estos actores tienen posiciones diferenciadas en un mercado de trabajo bastante fragmentado, y donde las relaciones obrero-patronales han sido desdibujadas por el uso de intermediarios laborales. La orientación de estos actores hacia el proceso de asentamiento parece estar organizada por un horizonte histórico de tiempo corto y de orden local, y a veces micro-local. El método de intervención, al propiciar el diálogo entre los sujetos de la acción colectiva, aliados y adversarios, permitió distinguir estos matices en el rostro de los sujetos de la acción colectiva, que no surgen necesariamente cuando se investiga con metodologías que privilegian la coherencia identitaria, oscureciendo los contrastes y las polémicas.

Recibido en junio de 2010 Aceptado en agosto de 2010

\section{Bibliografía}

Balibar, Etienne. 1991. Is there a Neo-racism? En Race, Nation, Class. Ambiguous Identities, editado por ídem., e Immanuel Wallerstein. Londres: Verso.

Barth, Fredrik. 1969. Introduction. En Ethnic Groups and Boundaries: The Social Organization of Cultural Difference, editado por ídem., 9-38. Londres: George Allen y Unwin.

Benmayor, Rina y Andor Skotnes. 2005. Some Reflections on Migration and Identity. En Migration and Identity, editado por ídem., 1-18. New Brunswick: Transaction Publishers. 
Bourdieu, Pierre. 2002. La distinción. Criterio y bases sociales del gusto. México: Taurus.

COLEF-CONACYT. 2003. Elaboración del proyecto "Migración trabajo agrícola y etnicidad”, con base en los datos del XII Censo general de población y vivienda, 2000, del Instituto Nacional de Estadística, Geografía e Informática.

COLEF-CONEPO. 2003. Encuesta a jornaleros agrícolas en campamentos del valle de San Quintín.

Cruz Aguirre, Javier. 1999. Cheques falsos. Semanario Zeta. 13 al 19 de agosto.

1996. San Quintín: niños trabajando en la pizca de tomate y hortalizas. Semanario Zeta. 29 de noviembre al 5 de diciembre.

Du Bry, Travis. 2003. The New Pioneers: Farm Laborers, Settlement and Community in the California Desert. Ponencia presentada en coloquio internacional Movilidad y construcción de los territorios de la multiculturalidad, de la Universidad Autónoma de Coahuila, Saltillo.

Edelman, Marc. 1991. Peasants Against Globalization. Rural Social Movements in Costa Rica. Stanford: Stanford University Press.

Giménez, Gilberto, 1994. El concepto de región. Apuntes para una teoría de la región y de la identidad regional. Estudios sobre las Culturas Contemporáneas vi (18): 165-173.

Kearney, Michael. 2008. La doble misión de las fronteras como clasificadores y como filtros de valor. En Migración, fronteras e identidades étnicas transnacionales, coordinado por Laura Velasco Ortiz, 79-110. Tijuana: COLEF y Miguel Ángel Porrúa.

Martínez Neira, Christian. 2008. ¿Qué son los movimientos étnicos? Las categorías de igualación y diferenciación. En Revisitar la 
etnicidad. Miradas cruzadas en torno a la diversidad, coordinado por Daniel Gutiérrez Martínez y Helene Balslev Clausen, 71-82. México: El Colegio de Sonora, El Colegio Mexiquense, Siglo xxi.

McDonald, Kevin. 2002. L'Intervention Sociologique. After Twenty Five Years: Can it Translate into English? Qualitative Sociology 25 (2): 247-60.

Melucci, Alberto. 1992. Frontier Land: Collective Action Between Actors and Systems. En Studyng Collective Action, editado por Mario Diani y Ron Eyerman, 238-258. Londres: Sage Publication. 1989. Nomads of the Present. Londres: Hutchinson Radius.

Ngai, M. 1999. The Architecture of Race in American Immigration Law: A Reexamination of the Immigration Act of 1924. The Journal of American History 86 (1): 67-92.

Passeron, Jean Claude. 1991. Le raisonnement sociologique. Paris: Nathan.

Rapport, Nigel y Andrew Dawson. 1989. The Topic and the Book. En Migrants of Identity. Perception of Home in aWorld of Movement, editado por ídem., 3-18. Nueva York: Berg.

Rosaldo, Renato. 1989. Culture and Truth: The Remaking of Social Analysis. Boston: Beacon Press.

Schmitt-Egner, Peter. 2002. The Concept of “Region”: Theoretical and Methodological Notes on its Reconstruction. European Integration 24 (3): 179-200.

Touraine, Alain. 1981. The Voice and the Eye:An Analysis of Social Movements. Cambridge: Cambridge University Press.

Velasco Ortiz, Laura. 2006. Proyecto "Migración, trabajo agrícola y etnicidad. La articulación de lo global, nacional y local en valle de San Quintín, Baja California”, CONACYT. 
2002. El regreso de la comunidad: migración indígena y agentes étnicos. Los mixtecos en la frontera México-Estados Unidos. México: El Colegio de México, COlEF. 